Article

\title{
Lightweight, Fiber-Damage-Resistant, and Healable Bio-Inspired Glass-Fiber Reinforced Polymer Laminate
}

\author{
Jia Long Liu ${ }^{1}$, Lorenzo Mencattelli ${ }^{2}$, Jie Zhi ${ }^{1}{ }^{1}$, Ping Yee Chua ${ }^{1}$, Tong-Earn Tay ${ }^{1}$ \\ and Vincent Beng Chye Tan ${ }^{1, * \mathbb{D}}$ \\ 1 Department of Mechanical Engineering, National University of Singapore, 9 Engineering Drive 1, \\ Singapore 117565, Singapore; e0011565@u.nus.edu (J.L.L.); jie.zhi@nus.edu.sg (J.Z.); \\ e0176357@u.nus.edu (P.Y.C.); mpetayte@nus.edu.sg (T.-E.T.) \\ 2 Helicoid Industries Inc., 82663 Redford Way, Indio, CA 92201, USA; lorenzom@helicoidind.com \\ * Correspondence: mpetanbc@nus.edu.sg
}

check for updates

Citation: Liu, J.L.; Mencattelli, L.; Zhi, J.; Chua, P.Y.; Tay, T.-E.; Tan, V.B.C. Lightweight,

Fiber-Damage-Resistant, and Healable Bio-Inspired Glass-Fiber Reinforced Polymer Laminate. Polymers 2022, 14, 475. https:// doi.org/10.3390/polym14030475

Academic Editor: Kwek-Tze Tan

Received: 16 December 2021

Accepted: 21 January 2022

Published: 25 January 2022

Publisher's Note: MDPI stays neutral with regard to jurisdictional claims in published maps and institutional affiliations.

Copyright: (C) 2022 by the authors. Licensee MDPI, Basel, Switzerland. This article is an open access article distributed under the terms and conditions of the Creative Commons Attribution (CC BY) license (https:// creativecommons.org/licenses/by/ $4.0 /$ )

\begin{abstract}
Glass-Fiber-Reinforced Polymer (GFRP) laminates are widely used in the automotive and marine industries such as auto bodies and boat hulls. Decreasing the weight and improving the reparability of GFRP parts will cut down material usage, fuel consumption and repair costs. This study shows a bio-inspired helicoidal stacking configuration that significantly improves the impact performance and fiber damage resistance of GFRP laminates. For similar impact performance in terms of perforation energy, the helicoidal GFRP laminate is $20 \%$ lighter than the conventional quasi-isotropic GFRP laminate. Upon impact, delaminations and matrix splits link-up and grow extensively throughout the helicoidal laminate. This effectively reduces fiber damage and improves impact performance. Because helicoidal GFRP laminates are resistant to fiber damage and composite healing agents can effectively repair non-fiber damage, embedding healing agents into helicoidal GFRP results in lightweight, inexpensive and healable laminates.
\end{abstract}

Keywords: lightweight; bio-inspired helicoidal structure; composite healing; impact; glass-fiber-reinforced polymer

\section{Introduction}

Glass-Fiber-Reinforced Polymer (GFRP) laminates have been widely adopted in the automotive and marine industries due to their low cost and good mechanical performance [1-3]. Since auto bodies and boat hulls require a large quantity of GFRP laminates, decreasing the weight of GFRP parts while maintaining their mechanical performance is beneficial for the industry and environment as it saves material costs and cuts down fuel consumption while meeting safety requirements. Improving the repair efficiency (cost/time ratio) of GFRP parts is also beneficial because damaged composite parts are expensive and difficult to repair [4]

Many researchers have attempted to strengthen and toughen GFRP parts by adding micro/nano-reinforcements [5-8] or by improving manufacturing processes [9]. However, many of these approaches increase either the material and/or fabrication cost. Since many high-volume composite components make extensive use of lower strength, lower cost GFRP laminates instead of higher performance and more costly Carbon-Fiber-Reinforced Polymer (CFRP) laminates, it is essential to develop design strategies to increase damage resistance, reduce weight, reduce material usage and reduce maintenance costs with GFRPs.

Drawing inspiration from nature, it is proposed that the mechanical performance of GFRP laminates can be improved through bio-inspired structural design. Many crustaceans' exoskeletons are composed of layers of aligned chitin fibers in a similar fashion to manmade fiber-reinforced polymer laminates [10]. The weak chitin fibers have to provide protection against out-of-plane loading and impact; at the same time, the exoskeleton also needs to be thin and light so as to not impair mobility nor increase energy consumption-a 
similar requirement for GFRP parts. Weaver et al. [10] investigated the microstructure of crustacean exoskeletons and found various mechanisms working in synergy to improve impact damage resistance. Most notable was the helicoidal structure of laminated chitin fibers [11].

In the helicoidal structure, the orientation of the fibers in one layer is offset at a slight angle with respect to the fibers in the layer below, forming a spiraling helicoidal configuration. Inspired by these findings, several researchers have conducted studies that mimic the helicoidal structure using CFRP laminates [12-26]. The results show that helicoidal layup significantly improves low-speed impact [12-17] and high-speed impact performance [18] of CFRP laminates. Furthermore, a recent study shows that the helicoidal structure also improved the high-speed impact perforation energy of natural fiber (flax)reinforced polymer composites by 30\% [20]. Since the strength and stiffness of glass fibers lie between carbon fiber and flax fiber, it is reasonable to expect that a helicoidal layup would also improve the impact performance of GFRP laminates. Many GFRP parts such as the roof of automobiles and boat hulls mainly provide protection against out-of-plane impact while the structural supports of these parts are provided by other components such as beams and trusses. Therefore, lightweight helicoidal GFRP laminates can offer an effective solution to enhance out-of-plane impact resistance and decrease structural weight.

Several studies $[18,20,22-26]$ reported that the helicoidal structure also reduces fiber damage in CFRP laminates as well as natural-fiber-reinforced polymer laminates. This is achieved by dissipating energy through mainly helicoidal matrix damage, namely, diffused matrix cracks and delaminations. With regard to conventional composites with high-performance fibers such as carbon and glass, matrix damage can be healed if a reprocessable matrix is used (e.g., thermoplastic) or if healing agents are dispersed within the matrix [26]; however, fiber damage is irreversible. Therefore, helicoidal GFRP laminates with an embedded healing agent may also possess good healing properties.

This study investigates the impact performance of helicoidal GFRP laminates together with conventional quasi-isotropic GFRP laminate as reference. Helicoidal GFRP laminates with fewer plies were fabricated to determine the percentage weight reduction achieved while maintaining similar impact performance as the reference laminate. A lightweight and healable helicoidal GFRP laminate was produced from investigating the damage patterns to understand the cause of failure.

\section{Experimental Setup}

\subsection{Fabrication Processes}

Quasi-isotropic and helicoidal laminates were fabricated from unidirectional G10000/6510 Glass fiber-epoxy prepregs. The mechanical properties of the material are shown in Table 1. Individual prepregs were cut into $100 \times 100 \mathrm{~mm}^{2}$ squares. They were then laid manually to form 61-ply quasi-isotropic and helicoidal laminates, as well as lighter 49-ply and 46-ply helicoidal configurations, as shown in Table 2.

The specimens were cured in an autoclave. The layups and curing cycle are shown in Figure 1 . The temperature was raised from room temperature to $130^{\circ} \mathrm{C}$ over $1 \mathrm{~h}$ and maintained for $1 \mathrm{~h}$. The specimens were then cooled over $1.5 \mathrm{~h}$ to room temperature resulting with an average laminate thickness of $4.5 \pm 0.05 \mathrm{~mm}$ for QI61 and HL61, $3.6 \pm 0.05 \mathrm{~mm}$ for HL49 and $3.4 \pm 0.05 \mathrm{~mm}$ for HL46.

\subsection{Perforation IMPACT Test}

Out-of-plane impact tests were conducted to evaluate the energy required to perforate the specimens. As shown in Figure 2, the specimens were placed on a plate with a $75 \mathrm{~mm}$ circular hole, which allows the specimens to flex under impact while providing an out-ofplane constraint that is independent of in-plane orientation. The specimens were impacted by a $12 \mathrm{~mm}$ diameter hemispherical impactor attached to a drop weight. The drop weight was set to drop from $50 \mathrm{~cm}$ height to achieve an impact velocity of $3.1 \mathrm{~m} / \mathrm{s}$. The drop weight mass can be increased or decreased, and the impact energy is adjustable with an interval 
of $1 \mathrm{~J}$. The perforation energy is taken as the lowest energy at which the test specimen is perforated.

Table 1. Mechanical and physical properties of G10000/6510 Glass fiber-epoxy prepreg.

\begin{tabular}{ccc}
\hline Property & Value & Remarks \\
\hline Ply thickness & $0.074 \mathrm{~mm}$ & \\
Ply areal density & $0.1475 \mathrm{~kg} / \mathrm{m}^{2}$ & ASTM D3039 \\
Modulus (fiber direction), $\mathrm{E}_{1}$ & $61.6 \mathrm{GPa}$ & ASTM D3039 \\
Modulus (Transverse direction), $\mathrm{E}_{2}$ & $11.8 \mathrm{Gpa}$ & ASTM D3039 \\
Tensile strength (fiber direction), $\sigma_{1 \mathrm{t}}$ & $1146 \mathrm{Mpa}$ & ASTM D6641 \\
Compressive strength (fiber direction), $\sigma_{1 \mathrm{c}}$ & $597 \mathrm{Mpa}$ & ASTM D3039 \\
Tensile strength (transverse direction), $\sigma_{2 \mathrm{t}}$ & ASTM D6641 \\
Compressive strength (transverse direction), $\sigma_{2 \mathrm{c}}$ & $110.5 \mathrm{Mpa}$ & ASTM D5528 \\
Interlaminar Mode I fracture toughness & $0.440 \mathrm{~mJ} / \mathrm{mm}^{2}$ & ASTM D7905/D7905M \\
Interlaminar Mode II fracture toughness & $1.12 \mathrm{~mJ} / \mathrm{mm}^{2}$ & [27] \\
Intralaminar Mode I fracture toughness (transverse direction), & $0.751 \mathrm{~mJ} / \mathrm{mm}^{2}$ & ASTM D2344
\end{tabular}

Table 2. Laminate configurations.

\begin{tabular}{cccccc}
\hline Designation & Description & $\begin{array}{c}\text { Laminate Area } \\
\text { Density }\end{array}$ & $\begin{array}{c}\text { Laminate } \\
\text { Thickness }\end{array}$ & $\begin{array}{c}\text { Weight } \\
\text { Against QI61 }\end{array}$ \\
\hline QI61 & 61 ply quasi-isotropic & $9 \mathrm{~kg} / \mathrm{m}^{2}$ & $4.5 \mathrm{~mm}$ & - & $(0 / 90 / 45 /-45)_{7} / 0 / 90 / 0 / 90 / 0 /(-45 / 45 / 90 / 0)_{7}$ \\
HL61 & 61 ply helicoidal & $9 \mathrm{~kg} / \mathrm{m}^{2}$ & $4.5 \mathrm{~mm}$ & $100 \%$ & $0 /-12 /-24 /-36 \ldots /-720$ \\
HL49 & 49 ply helicoidal & $7.2 \mathrm{~kg} / \mathrm{m}^{2}$ & $3.6 \mathrm{~mm}$ & $80.3 \%$ & $0 /-11.25 /-22.5 /-33.75 \ldots /-540$ \\
HL46 & 46 ply helicoidal & $6.8 \mathrm{~kg} / \mathrm{m}^{2}$ & $3.4 \mathrm{~mm}$ & $75.4 \%$ & $0 /-12 /-24 /-36 \ldots /-540$ \\
\hline
\end{tabular}

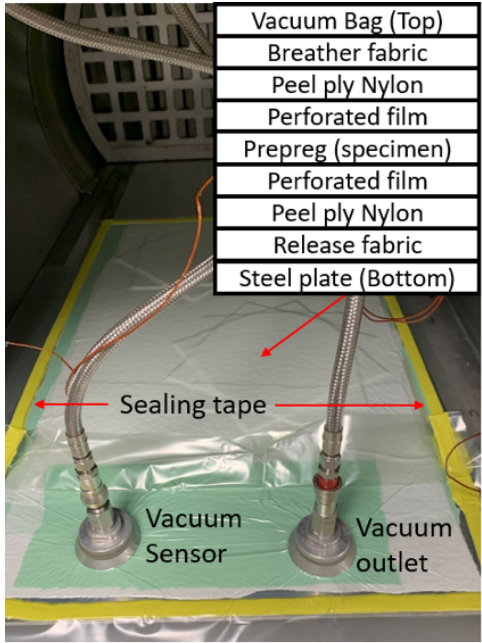

(a)

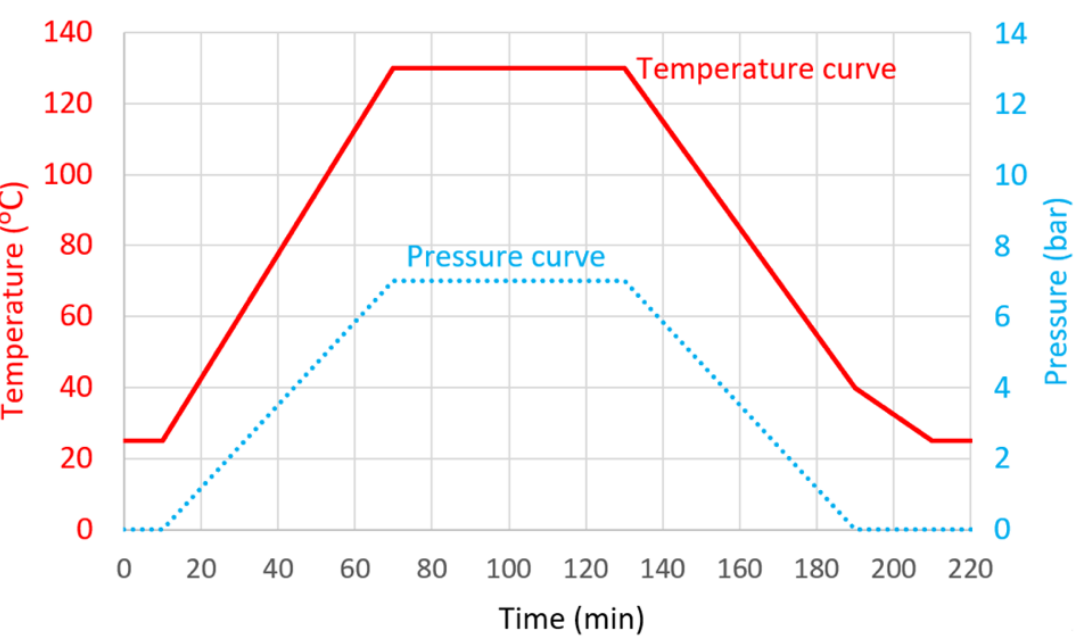

(b)

Figure 1. Laminate curing setup (a) and curing cycle (b).

\subsection{Fabrication Process of Healable Helicoidal GFRP Laminate}

Additional light weight helicoidal laminates that match the perforation energy of QI61 were fabricated and cured using the same process as described in Section 2.1, except with an additional healing agent $(0.95 \%$ weight fraction, Nylon6 healing agent $[26,28])$.

Dispersing healing agents within plies is commonly adopted for composite healing [29-33]. The healing agent is in a form of micro-capsules (self-healing healing agent) or powder (thermoplastic healing agent) and is mixed with resin and dispersed into each ply, as shown in Figure 3a. Thermoplastic healing agents melt under heat and flow into nearby cracks under pressure, healing the epoxy cracks, as shown in Figure 3a. However, the 
melted healing agents may not fully spread across the entire delaminated interface because most healing agents are dispersed within the plies. Since delamination is a dominant damage in helicoidal laminates [12,22], it is more effective to apply healing agents between plies as shown in Figure 3b. Therefore, healable specimens were produced with a Nylon6 healing agent added between plies, as shown in Figure 4.

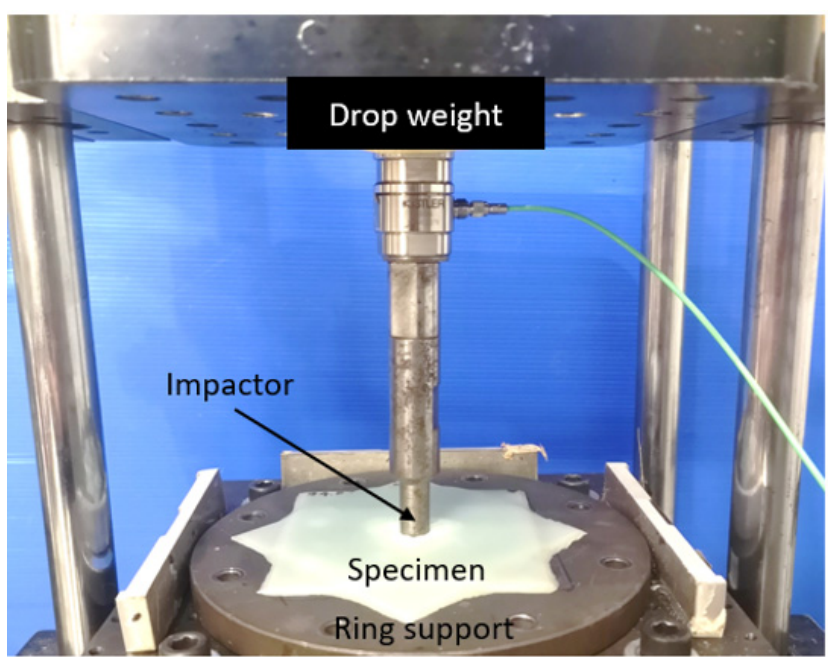

(a)

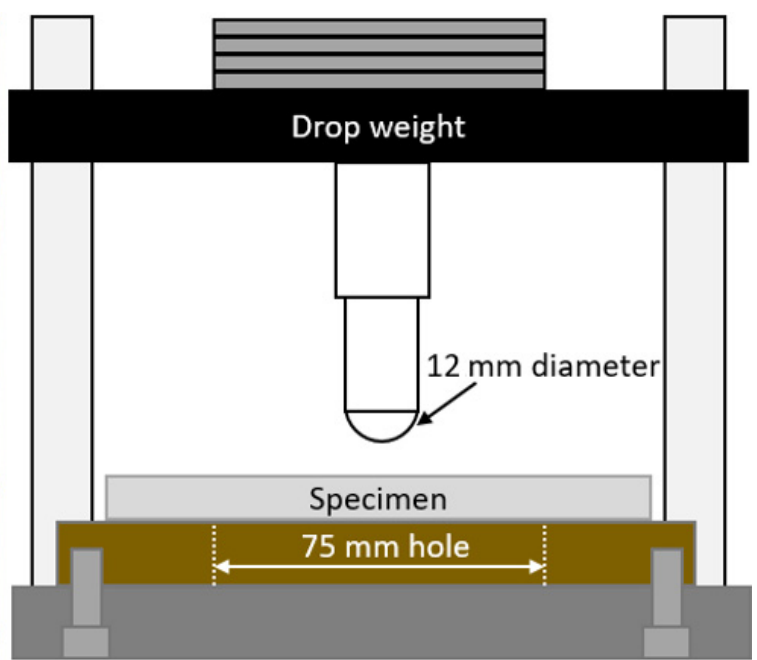

(b)

Figure 2. Drop test experimental setup (a) and schematic diagram of the test (b).

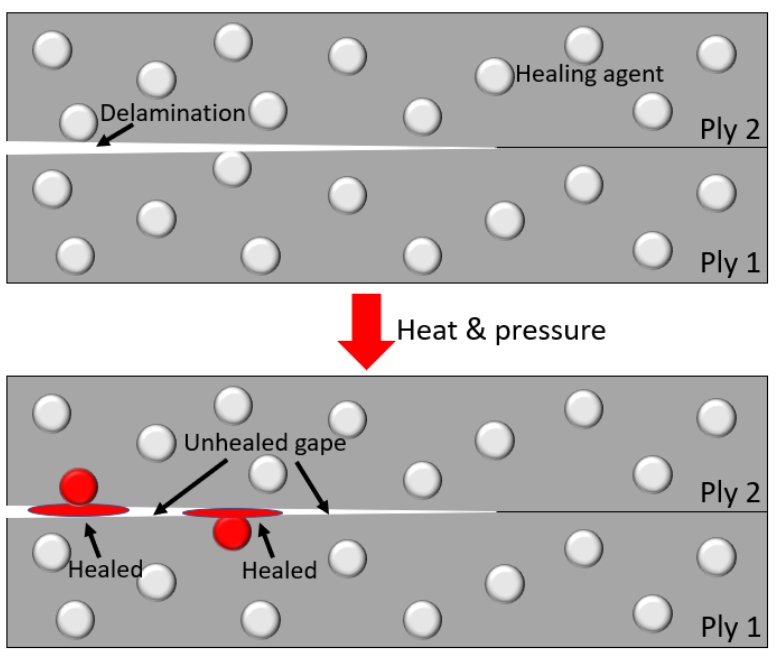

(a)

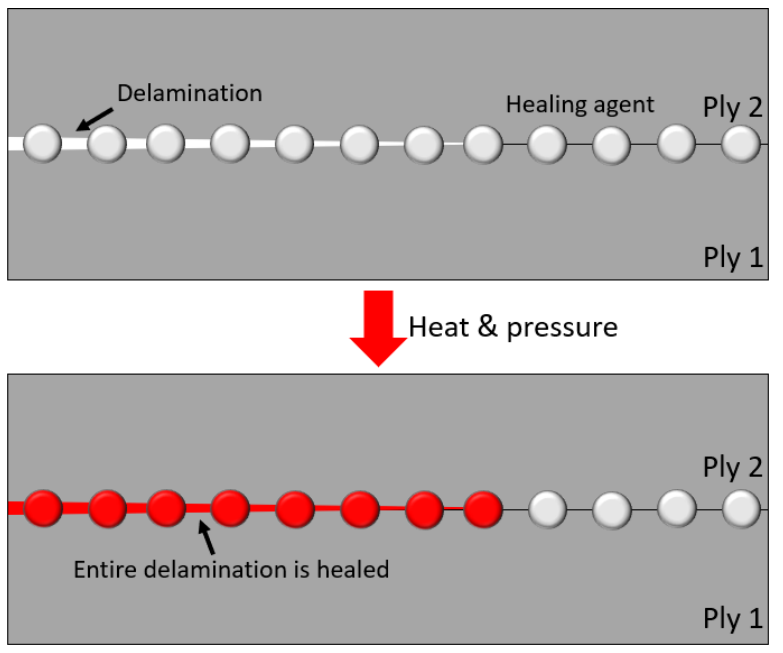

(b)

Figure 3. Dispersed healing agent within plies (a), healing agent between plies (b).

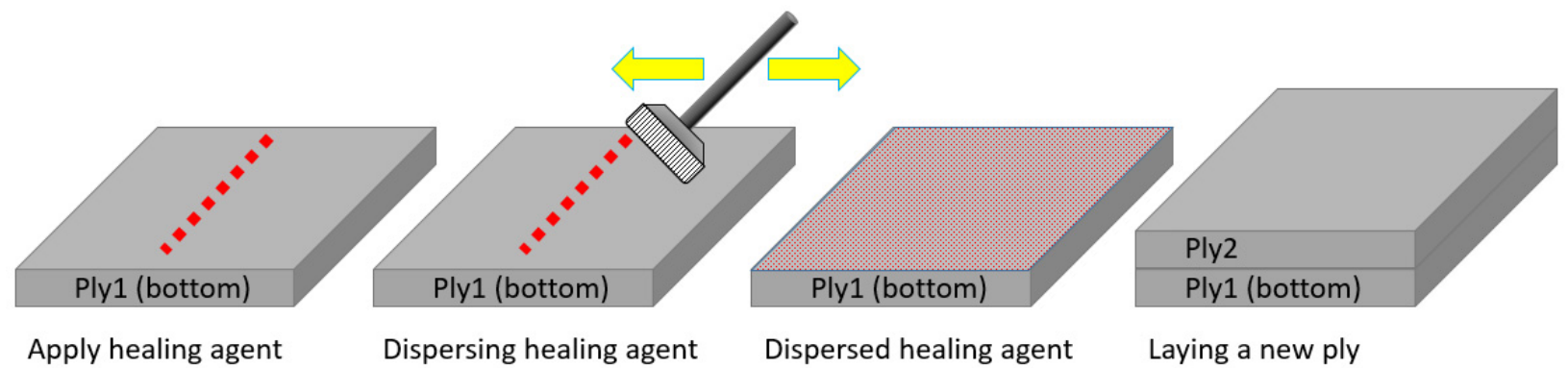

Figure 4. Schematic diagram of the healable laminate fabrication process. 


\subsection{Impact and Healing of Helicoidal GFRP Laminate}

The healable specimens were then subjected to a low energy impact. After impact, the damaged specimens were healed in a hot-press. The specimen was firstly heated to $200{ }^{\circ} \mathrm{C}$ over $10 \mathrm{~min}$ to soften the healing agent before a pressure of 2 bar was applied. The specimen was then heated to $220{ }^{\circ} \mathrm{C}$ over $20 \mathrm{~min}$ to allow the Nylon6 healing agent to melt and flow into the cracks. The specimen was then cooled to room temperature over $15 \mathrm{~min}$.

\section{Results and Discussion}

As shown in Table 3 and Figure 5, the perforation energy of HL61 is $48 \%$ higher than QI61. This shows that the impact performance of GFRP laminates can be significantly improved by stacking the laminate helicoidally. The perforation energy of HL49 is $1 \mathrm{~J}$ lower than QI61, but it is 20\% lighter in weight. The perforation energy of HL46 is $6 \mathrm{~J}$ lower than QI61. Since HL49 provided the closest value of perforation energy compared to QI61, additional QI61, HL61 and HL49 were subjected to a 16 J impact to inspect their damage pattern under lower energy impacts.

Table 3. Perforation impact test results.

\begin{tabular}{cccc}
\hline Designation & Specimen No. & Impact Energy (J) & Perforation \\
\hline QI61 & 1 & 50 & No \\
& 2 & 60 & No \\
& 3 & 70 & Yes \\
4 & 65 & No \\
& 5 & 68 & Yes \\
& 6 & 66 & No \\
& 7 & 67 & Yes \\
& 8 & 66 & Yes \\
HL61 & 9 & 61 & No \\
& 1 & 80 & No \\
& 2 & 100 & Yes \\
& 3 & 97 & No \\
& 4 & 98 & No \\
& 5 & 99 & Yes \\
& 6 & 98 & Yes \\
& 7 & 94 & No \\
& 1 & 66 & Yes \\
& 2 & 60 & No \\
& 3 & 65 & No \\
& 4 & 64 & No \\
& 5 & 66 & Yes \\
& 5 & 65 & No \\
& 6 & 60 & No \\
& 6 & 63 & Yes \\
& 1 & 61 & Yes \\
& 3 & 60 & No \\
\hline & 5 & 59 &
\end{tabular}

As shown in Figures 6 and 7, the helicoidal GFRP laminates clearly show highly diffused spiraling delamination damage. The extent of delamination is small near the bottom of the laminate but increases dramatically from the bottom towards the middle of the laminate, and it then decreases near the top of the laminate. The delamination in each interface rotates by a small angle from the previous one, and these delaminations are linked by matrix splits and spiral upwards, similar to a pair of spiral staircases. This is the unique damage pattern of helicoidally stacked fiber-reinforced laminates and is referred to as a spiraling matrix split [18,22,25]. Liu et al. [25] and Suksangpanya et al. [34] reported that spiraling matrix split is a form of matrix crack that grows between fibers. The resistance to the propagation of a spiraling matrix split in a helicoidal laminate decreases as the inter-ply 
angle of the laminate decreases [34], and the spiraling matrix split propagates extensively in helicoidally stacked laminates with small inter-ply angles, such as in the cases of HL61 and HL49.

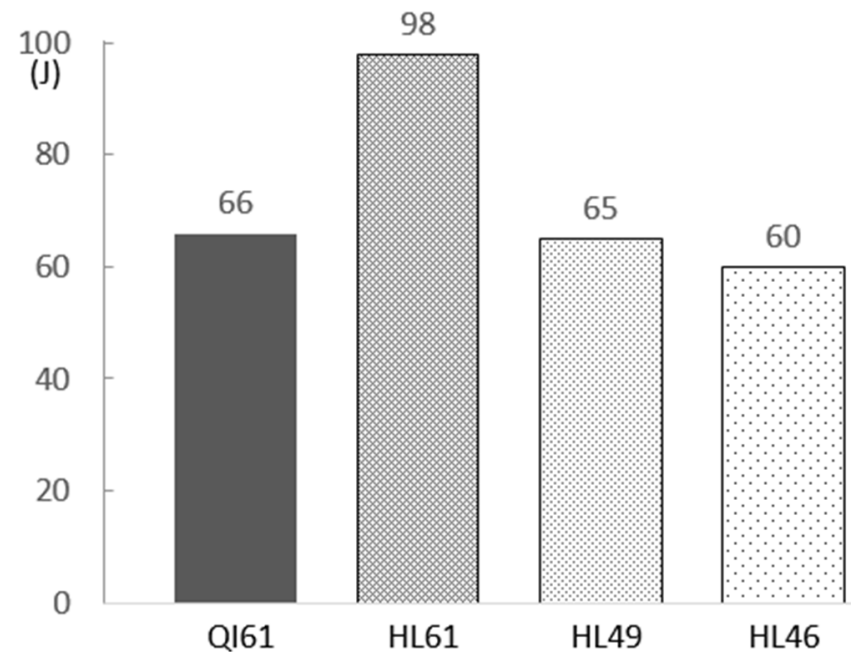

Figure 5. Perforation energy of the specimens.
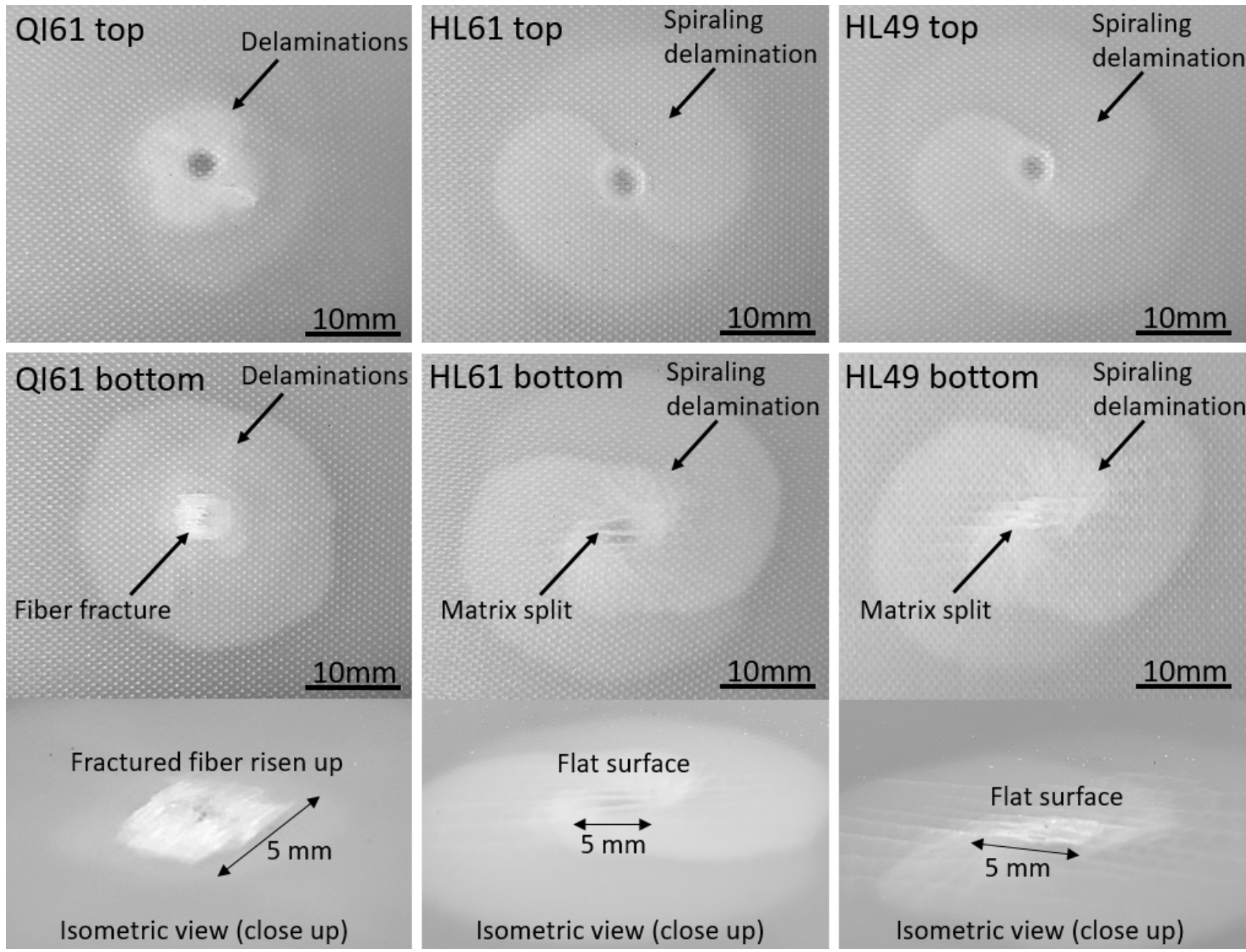

Isometric view (close up)

Isometric view (close up)

Isometric view (close up)

Figure 6. Damage to the specimens after low energy (16 J) impact. 


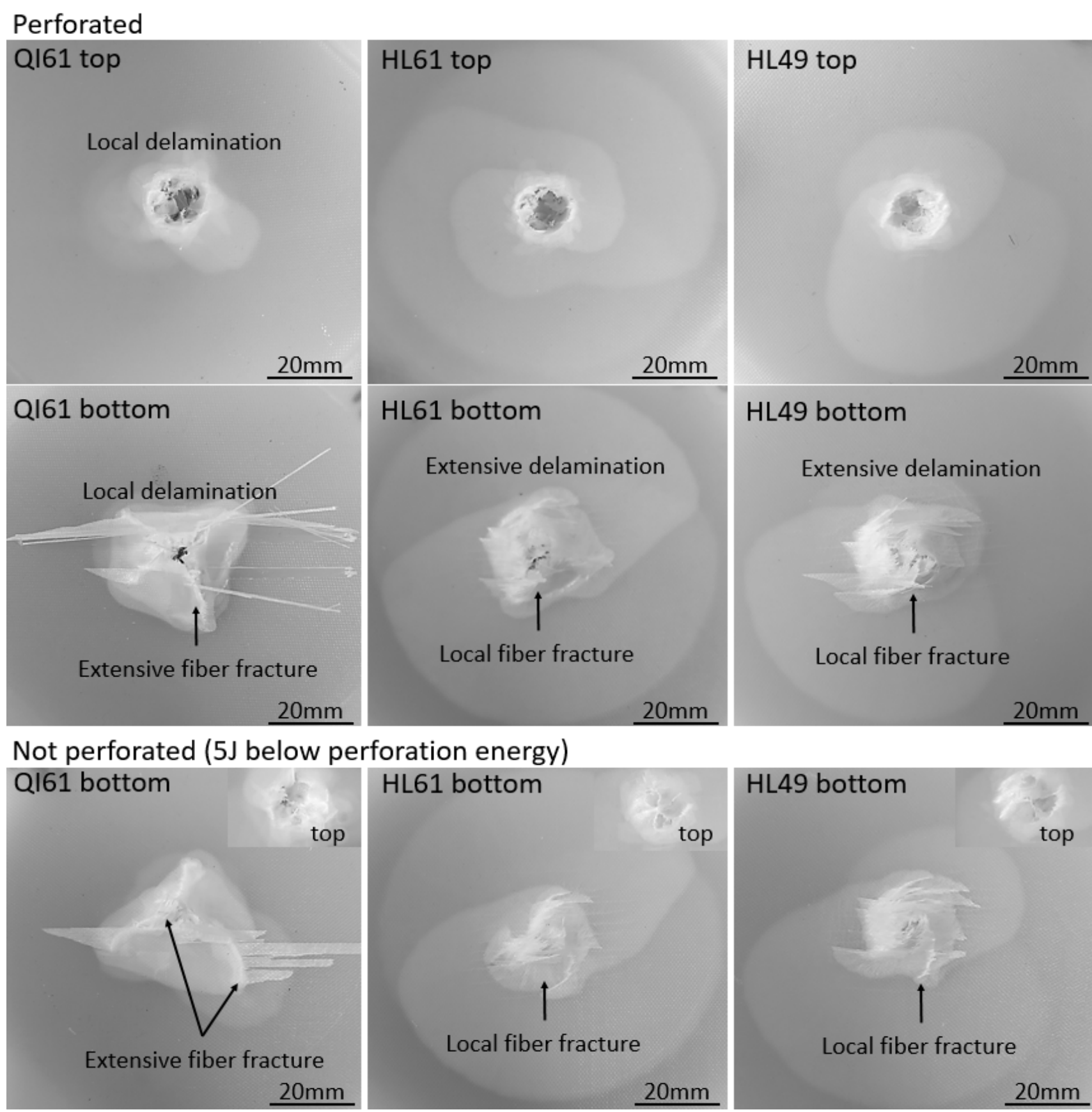

Figure 7. Damage to the perforated and nearly perforated samples.

Although spiraling matrix split was deduced through theoretical study and experimental CT-scan by Suksangpanya et al. [34] and Liu et al. [22], respectively. Figures 6 and 7 show, for the first time, the images of the spiraling matrix split directly observable from the surface of the composite. This was possible due to the semitransparency of GFRP laminates. The pair of spiraling matrix splits in HL61 are almost identical, whereas one of the spiraling matrix splits in HL49 was more extensive when the impact energy reached perforation energy. This is mainly related to the fact that the HL61 has a more balanced 4 revolutions ( 1 revolution is $180^{\circ}$ ) from $0^{\circ}$ to $720^{\circ}$ while $\mathrm{HL} 49$ has an unbalanced 3 revolutions from $0^{\circ}$ to $540^{\circ}$, so the spiraling matrix split tends to develop unevenly in HL49 when the impact energy is large.

As shown in Figure 6, under the same $16 \mathrm{~J}$ low energy impact, fiber damage is developed at the bottom of QI61. Despite more extensive matrix cracks, no fiber damage is 
observed at the bottom surface of HL61 and HL49. As shown in Figure 7, fiber damage extends beyond the point of impact in perforated QI61, whereas fiber damage is contained within a narrower region in perforated HL61 and HL49. When impact energy is $5 \mathrm{~J}$ lower than the perforation energy of each laminate, extensive fiber damage is again observed at the bottom of QI61 while minimal fiber damage is observed at the bottom of HL61 and HL49. On the other hand, delamination in QI61 is localized compared to the size of the spiraling matrix split in HL61 and HL49.

The reduction in fiber damage in helicoidal laminates is a consequence of the extensive sub-critical spiraling matrix split. The highly diffused combination of matrix splits and delaminations in the spiraling matrix split reduces stresses along the fiber direction which minimizes fiber damage [35-38]. As a result, under different impact intensities, fiber damage is the dominant damage in quasi-isotropic GFRP laminates whilst both spiraling matrix split and fiber damage are prevalent in helicoidal GFRP laminates.

Perforation of GFRP laminates is the result of an impactor breaking through the fibers along its path. Since helicoidal GFRP laminates are more resistant to fiber damage and the impact energy is dissipated through fiber damage as well as the massive spiraling matrix split, this is the reason why helicoidal GFRP laminate excels in impact performance.

Several studies on composite intrinsic healing technology have shown that damaged epoxy resin can be healed effectively with thermoplastic healing agents [30-33]. On the other hand, damaged fibers in the composite will not recover their full strength after healing because the healing agent is weaker than the fibers. The healing agent simply bonds the fractured fibers and leaves a weak spot. Since fiber damage is diverted to delamination and matrix damage during impact for helicoidal GFRP laminates, helicoidal GFRP laminates with embedded healing agents would facilitate good healing.

HL49 specimens with embedded Nylon6 healing agent following the fabrication process described in Section 2.3 were produced. In addition, they were then subjected to $16 \mathrm{~J}$ impact and healed following the process described in Section 2.4. As shown in Figure 8, the damage within the healable HL49 after impact is similar to the HL49 without healing agents shown in Figure 6. The spiraling matrix split is developed near the point of impact with an extensive matrix split at the bottom surface of the laminate. After the healing process, most of the cracks have closed up except for a few superficial cracks at the bottom of the laminate.

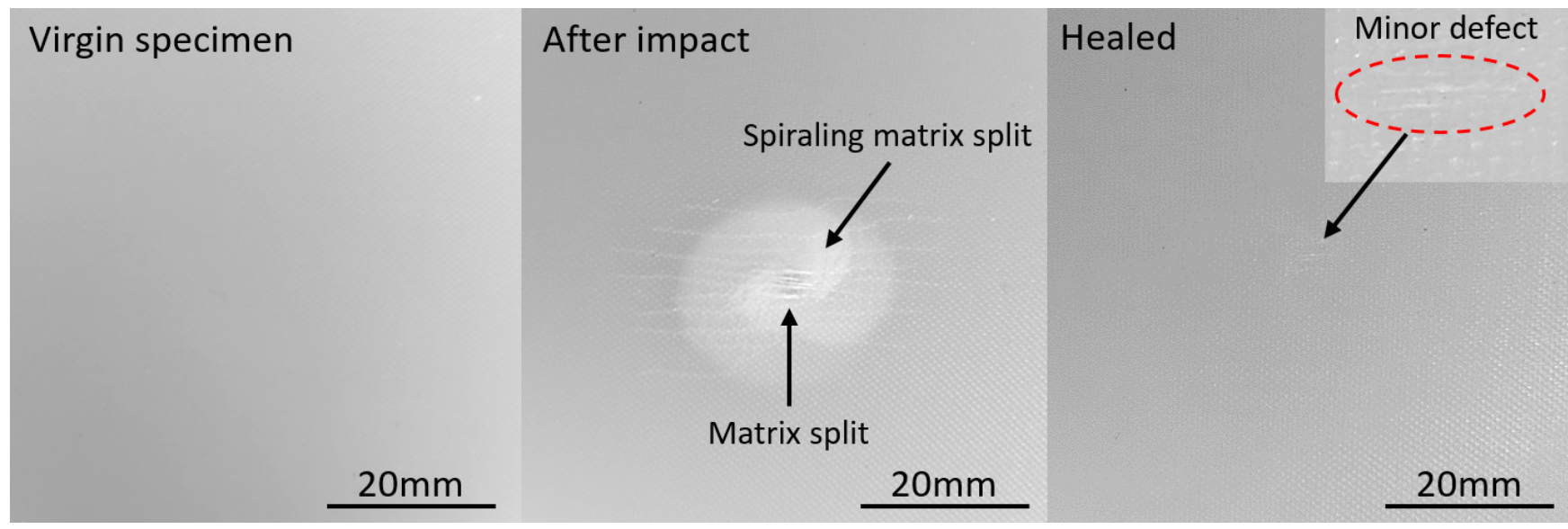

Figure 8. Bottom surface of healable HL49 specimen after impact and after healing.

The result shows that by adding a small amount of healing agent between each ply, the GFRP helicoidal laminates can achieve good healing after low energy impact.

\section{Conclusions}

This study shows that by stacking GFRP laminate helicoidally, the weight of the laminates can be reduced by $20 \%$ while maintaining the same perforation energy as the 
conventional quasi-isotropic GFRP laminate under impact. Since a large quantity of GFRP laminates are used in the automotive and marine industry as auto body parts and boat hulls, and since the lighter helicoidal GFRP laminates can meet the same safety requirement as the conventional GFRP laminate, adopting helicoidal GFRP laminates is beneficial for the industry and the environment as it saves material and cuts down fuel consumption while not introducing additional costs.

During impact, a highly diffused spiraling matrix split develops in helicoidal GFRP laminates, reducing fiber damage. In contrast, damage is highly localized in conventional GFRP quasi-isotropic laminates, leading to localized delaminations and extensive fiber damage. Helicoidal GFRP laminates are more resistant to perforation because of the better resistance to fiber damage and the development of diffused spiraling matrix splits. Helicoidal GFRP laminates thus show reduced fiber damage under low energy impact. As such, healable helicoidal GFRP laminate can be produced by simply adding thermoplastic healing agents between plies.

Author Contributions: Conceptualization, J.L.L.; Data curation, P.Y.C.; Formal analysis, J.L.L.; Funding acquisition, T.-E.T.; Investigation, J.L.L.; Methodology, J.L.L.; Project administration, T.-E.T.; Resources, T.-E.T.; Supervision, V.B.C.T.; Writing—original draft, J.L.L.; Writing—review \& editing, L.M., J.Z. and V.B.C.T. All authors have read and agreed to the published version of the manuscript.

Funding: The support through Agency for Science, Technology and Research (Singapore) grant reference no. A19C1a0044 (WP 1-1), (WBS R-265-000-673-305) is gratefully acknowledged. We thank the Helicoid Industries Inc. for providing the insight for adopting helicoidal technology for GFRP laminate.

Institutional Review Board Statement: Not applicable.

Informed Consent Statement: Not applicable.

Data Availability Statement: The data presented in this study are available on request from the corresponding author.

Conflicts of Interest: The authors declare no conflict of interest.

\section{References}

1. Thomason, J.L. Glass fibre sizing: A review. Compos. Part A Appl. Sci. Manuf. 2019, 127, 105619. [CrossRef]

2. Zisimopoulos, D.A. Use of Fiber Reinforced Plastics in Ship Construction: A Study of SOLAS Regulation II-2/17 on Alternative Design and Arrangementsfor Fire Safety. 2016. Available online: https://dspace.lib.ntua.gr/xmlui/handle/123456789/42464 (accessed on 15 December 2021).

3. Park, C.K.; Kan, C.D.S.; Hollowell, W.T.; Hill, S.I. Investigation of Opportunities for Lightweight Vehicles Using Advanced Plastics and Composites. 2012. Available online: https:/ / trid.trb.org/view/1226276 (accessed on 15 December 2021).

4. Katnam, K.; Da Silva, L.; Young, T. Bonded repair of composite aircraft structures: A review of scientific challenges and opportunities. Prog. Aerosp. Sci. 2013, 61, 26-42. [CrossRef]

5. Ozdemir, N.G.; Zhang, T.; Hadavinia, H.; Aspin, I.; Scarpa, F. Glass fibre reinforced polymer composites toughened with acrylonitrile butadiene nanorubber. Compos. Part B Eng. 2016, 88, 182-188. [CrossRef]

6. Ngah, S.A.; Taylor, A.C. Toughening performance of glass fibre composites with core-shell rubber and silica nanoparticle modified matrices. Compos. Part A Appl. Sci. Manuf. 2016, 80, 292-303. [CrossRef]

7. Singh, K.K.; Nanda, T.; Mehta, R. Addition of nanoclay and compatibilized EPDM rubber for improved impact strength of epoxy glass fiber composites. Compos. Part A Appl. Sci. Manuf. 2017, 103, 263-271. [CrossRef]

8. Uribe, B.B.; Chiromito, E.; Carvalho, A.; Arenal, R.; Tarpani, J. TEMPO-oxidized cellulose nanofibers as interfacial strengthener in continuous-fiber reinforced polymer composites. Mater. Des. 2017, 133, 340-348. [CrossRef]

9. Luo, G.; Liu, G.; Chen, Y.; Liang, W.; Liu, G.; Niu, Y.; Li, G. High performance glass fiber reinforced polypropylene realized by reactive extrusion technology. Compos. Sci. Technol. 2018, 165, 198-205. [CrossRef]

10. Weaver, J.C.; Milliron, G.W.; Miserez, A.; Evans-Lutterodt, K.; Herrera, S.; Gallana, I.; Mershon, W.J.; Swanson, B.; Zavattieri, P.; DiMasi, E.; et al. The Stomatopod Dactyl Club: A Formidable Damage-Tolerant Biological Hammer. Science 2012, 336, 1275-1280. [CrossRef]

11. Bouligand, Y. Sur une architecture torsadee repandue dans de nombreuses cuticules d'arthropodes. C. R. Acad. Sci. 1965, 261, 3665-3668.

12. Mencattelli, L.; Pinho, S.T. Ultra-thin-ply CFRP Bouligand bio-inspired structures with enhanced load-bearing capacity, delayed catastrophic failure and high energy dissipation capability. Compos. Part A Appl. Sci. Manuf. 2020, 129, 105655. [CrossRef] 
13. Apichattrabrut, T.; Ravi-Chandar, K. Helicoidal Composites. Mech. Adv. Mater. Struct. 2006, 13, 61-76. [CrossRef]

14. Grunenfelder, L.; Suksangpanya, N.; Salinas, C.; Milliron, G.; Yaraghi, N.; Herrera, S.; Evans-Lutterodt, K.; Nutt, S.; Zavattieri, P.; Kisailus, D. Bio-inspired impact-resistant composites. Acta Biomater. 2014, 10, 3997-4008. [CrossRef] [PubMed]

15. Jiang, H.; Ren, Y.; Liu, Z.; Zhang, S.; Lin, Z. Low-velocity impact resistance behaviors of bio-inspired helicoidal composite laminates with non-linear rotation angle based layups. Compos. Struct. 2019, 214, 463-475. [CrossRef]

16. Körbelin, J.; Goralski, P.; Kötter, B.; Bittner, F.; Endres, H.-J.; Fiedler, B. Damage tolerance and notch sensitivity of bio-inspired thin-ply Bouligand structures. Compos. Part C Open Access 2021, 5, 100146. [CrossRef]

17. Ginzburg, D.; Pinto, F.; Iervolino, O.; Meo, M. Damage tolerance of bio-inspired helicoidal composites under low velocity impact. Compos. Struct. 2017, 161, 187-203. [CrossRef]

18. Liu, J.; Singh, A.; Lee, H.; Tay, T.; Tan, V. The response of bio-inspired helicoidal laminates to small projectile impact. Int. J. Impact Eng. 2020, 142, 103608. [CrossRef]

19. Ouyang, W.; Gong, B.; Wang, H.; Scarpa, F.; Su, B.; Peng, H.-X. Identifying optimal rotating pitch angles in composites with Bouligand structure. Compos. Commun. 2020, 23, 100602. [CrossRef]

20. Chew, E.; Liu, J.; Tay, T.; Tran, L.; Tan, V. Improving the mechanical properties of natural fibre reinforced laminates composites through Biomimicry. Compos. Struct. 2021, 258, 113208. [CrossRef]

21. Yang, F.; Yi, F.; Xie, W. The role of ply angle in interlaminar delamination properties of CFRP laminates. Mech. Mater. 2021, 160, 103928. [CrossRef]

22. Liu, J.L.; Lee, H.; Tan, V. Effects of inter-ply angles on the failure mechanisms in bioinspired helicoidal laminates. Compos. Sci. Technol. 2018, 165, 282-289. [CrossRef]

23. Liu, J.; Lee, H.; Kong, S.; Tan, V. Improving laminates through non-uniform inter-ply angles. Compos. Part A Appl. Sci. Manuf. 2019, 127, 105625. [CrossRef]

24. Plocher, J.; Mencattelli, L.; Narducci, F.; Pinho, S. Learning from nature: Bio-inspiration for damage-tolerant high-performance fibre-reinforced composites. Compos. Sci. Technol. 2021, 208, 108669. [CrossRef]

25. Liu, J.L.; Lee, H.P.; Lai, K.S.; Tan, V.B.; Long, L.J. Bio-Inspired Laminates of Different Material Systems. J. Appl. Mech. 2019, 87, 031007. [CrossRef]

26. Liu, J.; Lee, H.; Tay, T.; Tan, V. Healable bio-inspired helicoidal laminates. Compos. Part A Appl. Sci. Manuf. 2020, 137, 106024. [CrossRef]

27. Czabaj, M.W.; Ratcliffe, J.G. Comparison of intralaminar and interlaminar mode I fracture toughnesses of a unidirectional IM7/8552 carbon/epoxy composite. Compos. Sci. Technol. 2013, 89, 15-23. [CrossRef]

28. Kostopoulos, V.; Kotrotsos, A.; Tsokanas, P.; Tsantzalis, S. Toughening and healing of composites by CNTs reinforced copolymer nylon micro-particles. Mater. Res. Express 2018, 52, 025305. [CrossRef]

29. Pingkarawat, K.; Bhat, T.; Craze, D.A.; Wang, C.H.; Varley, R.J.; Mouritz, A.P. Healing of carbon fibre-epoxy composites using thermoplastic additives. Polym. Chem. 2013, 4, 5007-5015. [CrossRef]

30. Selver, E.; Potluri, P.; Soutis, C.; Hogg, P. Healing potential of hybrid materials for structural composites. Compos. Struct. 2015, 122, 57-66. [CrossRef]

31. Hayes, S.A.; Jones, F.R.; Marshiya, K.; Zhang, W. A self-healing thermosetting composite material. Compos. Part A Appl. Sci. Manuf. 2007, 38, 1116-1120. [CrossRef]

32. Meure, S.; Wu, D.Y.; Furman, S. Polyethylene-co-methacrylic acid healing agents for mendable epoxy resins. Acta Mater. 2009, 57, 4312-4320. [CrossRef]

33. Meure, S.; Varley, R.J.; Wu, D.Y.; Mayo, S.; Nairn, K.; Furman, S. Confirmation of the healing mechanism in a mendable EMAA-epoxy resin. Eur. Polym. J. 2012, 48, 524-531. [CrossRef]

34. Suksangpanya, N.; Yaraghi, N.A.; Kisailus, D.; Zavattieri, P. Twisting cracks in Bouligand structures. J. Mech. Behav. Biomed. Mater. 2017, 76, 38-57. [CrossRef] [PubMed]

35. Hajikazemi, M.; McCartney, L.; Van Paepegem, W. Matrix cracking initiation, propagation and laminate failure in multiple plies of general symmetric composite laminates. Compos. Part A Appl. Sci. Manuf. 2020, 136, 105963. [CrossRef]

36. Hajikazemi, M.; Garoz, D.; Van Paepegem, W. Model to accurately predict out-of-plane shear stiffness reduction in general cracked laminates. Compos. Sci. Technol. 2019, 179, 88-96. [CrossRef]

37. Hajikazemi, M.; McCartney, L.; Ahmadi, H.; Van Paepegem, W. Variational analysis of cracking in general composite laminates subject to triaxial and bending loads. Compos. Struct. 2020, 239, 111993. [CrossRef]

38. Sebaey, T.; González, E.V.; Lopes, C.; Blanco, N.; Costa, J. Damage resistance and damage tolerance of dispersed CFRP laminates: Effect of ply clustering. Compos. Struct. 2013, 106, 96-103. [CrossRef] 